\title{
Variability of the Kuroshio Extension Jet, Recirculation Gyre, and Mesoscale Eddies on Decadal Time Scales
}

\author{
Bo Qiu And Shuiming Chen \\ Department of Oceanography, University of Hawaii at Manoa, Honolulu, Hawaii
}

(Manuscript received 5 October 2004, in final form 13 April 2005)

\begin{abstract}
Twelve years of sea surface height (SSH) data from multiple satellite altimeters are used to investigate the low-frequency changes and the interconnections of the Kuroshio Extension (KE) jet, its southern recirculation gyre, and their mesoscale eddy field. The dominant signal is characterized by the steady weakening of the KE jet/recirculation gyre from 1993 to 1996, followed by a gradual strengthening after 1997. During the weakening period of 1993-96, the KE path migrated southward in general, and this path migration reversed in direction during the strengthening period of the KE jet and recirculation gyre after 1997. By hindcasting the SSH signals using linear vorticity dynamics, it was found that weakening (strengthening) in the KE jet and recirculation gyre is consistent with westward propagation of negative (positive) $\mathrm{SSH}$ anomalies generating in the eastern North Pacific and strengthening during their westward propagation. When the KE jet and recirculation gyre were in a weak mode during 1996-2001, the regional eddy kinetic energy level was observed to be higher than when the jet and recirculation gyre were in a strong mode. This negative correlation between the mean flow intensity and the level of regional eddy kinetic energy is found in both the SSH data and the linear vorticity model to result from the migration of the KE jet inflow over the Izu-Ogasawara Ridge. When it is forced southward by the impinging negative SSH anomalies, the KE jet inflow rides over the ridge through a shallow segment, leading to large-amplitude downstream meanders. Impinging of positive SSH anomalies, on the other hand, strengthens the recirculation gyre and forces the inflow northward where it passes through a deep channel, minimizing the path perturbations in the downstream region.
\end{abstract}

\section{Introduction}

The Kuroshio Extension (KE) is the western boundary current extension of the subtropical gyre in the North Pacific Ocean. After separating from the coast of Japan near $35^{\circ} \mathrm{N}$, the mean path of the upstream KE is characterized by the presence of two quasi-stationary meanders with their ridges located at $144^{\circ}$ and $150^{\circ} \mathrm{E}$, respectively (Fig. 1). These quasi-stationary meanders were interpreted by Mizuno and White (1983) as standing Rossby lee waves generated by the Izu-Ogasawara Ridge along $140^{\circ} \mathrm{E}$ (see Fig. 1 for the regional bathymetry), although Hurlburt et al. (1996) have recently argued that the meanders are steered by the eddy-driven abyssal mean flows resulting from instability of the deep KE jet.

Corresponding author address: Dr. Bo Qiu, Department of Oceanography, University of Hawaii at Manoa, 1000 Pope Road, Honolulu, HI 96822.

E-mail: bo@soest.hawaii.edu
South of the quasi-stationary meanders, the KE jet is flanked by a tight recirculation gyre, whose existence has been observed to increase the eastward transport of the KE from the local Sverdrup transport value of $\sim 50$ to $\sim 130 \mathrm{~Sv}$ (where $1 \mathrm{~Sv} \equiv 10^{6} \mathrm{~m}^{3} \mathrm{~s}^{-1}$; Wijffels et al. 1998). Near $159^{\circ} \mathrm{E}$, the KE jet encounters the Shatsky Rise where it often bifurcates: the main body of the jet continues eastward, and a secondary branch tends to move northeastward to $40^{\circ} \mathrm{N}$ where it joins the Subarctic Current (e.g., Mizuno and White 1983; Niiler et al. 2003). With the broadening in its width downstream of $160^{\circ} \mathrm{E}$, the $\mathrm{KE}$ loses its inertial jet characteristics (e.g., Joyce 1987) and rejoins gradually the interior Sverdrup circulation as the North Pacific Current.

Free from the constraint of coastal boundaries, and with the transport enhanced by the southern recirculation gyre, the KE east of Japan has long been observed to be rich in large-amplitude meanders and energetic pinched-off eddies (Mizuno and White 1983; Kawamura et al. 1986; Yasuda et al. 1992). The advent of high-precision satellite altimeters in recent decades has 


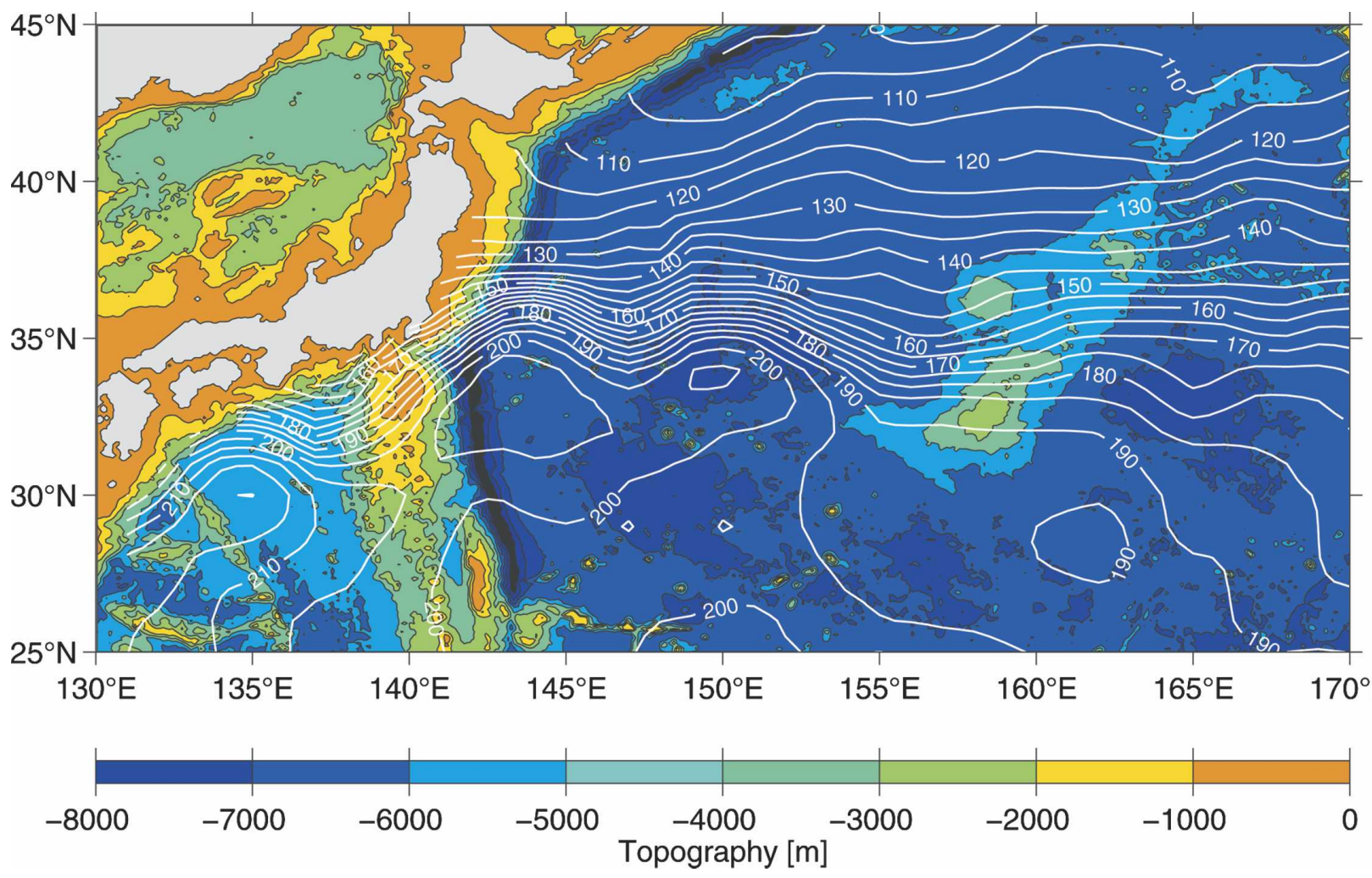

FIG. 1. Surface dynamic height field (cm; white contours) relative to 1000 dbar from Teague et al. (1990). Colored map shows the bathymetry based on Smith and Sandwell (1994). Major bathymetric features in the region include the Izu-Ogasawara Ridge along $140^{\circ} \mathrm{E}$ and the Shatsky Rise around $159^{\circ} \mathrm{E}$.

significantly advanced our knowledge of the mesoscale variability of the global oceans. Indeed, a rich literature now exists that has examined the propagation, the seasonality, and the interaction with the mean $\mathrm{KE}$ jet of the mesoscale eddies based on altimetrically derived sea surface height (SSH) data (Tai and White 1990; Aoki et al. 1995; Qiu 1995; Mitchell et al. 1996; Wang et al. 1998; Adamec 2000; Ebuchi and Hanawa 2001; Ducet and Le Traon 2001; Mitsudera et al. 2001; among others).

Located at the crossroads between the subtropical and subpolar gyres of the North Pacific, mesoscale eddy variability in the $\mathrm{KE}$ region has been emphasized by several recent studies to be important in facilitating water mass exchanges and transformations across the gyre boundary (e.g., Yasuda et al. 1996; Talley 1997; Joyce et al. 2001). In addition, the eddy variability has also been found to play an important role in determining the surface ocean heat budget and the overlying atmospheric boundary layer wind in the region (Qiu and Kelly 1993; Vivier et al. 2002; Nonaka and Xie 2003).

To date, studies of the mesoscale eddies in the KE region have not considered the broader scale circulation changes. As will be seen in this study, significant changes have occurred in the path and mesoscale eddy field of the $\mathrm{KE}$ and its recirculation gyre over the past $12 \mathrm{yr}$. This points to the need to examine the KE jet, its recirculation gyre, and the mesoscale eddy field as an interconnected dynamic system. Using the decade-long (October 1992-December 2004) SSH data from multiple satellite missions, we will first quantify the lowfrequency changes detected in the KE system. The existence of a stable versus an unstable mode of the KE system is emphasized. We then seek to relate the recirculation gyre variability to large-scale, wind-driven thermocline changes using a linear vorticity model. Based on both the SSH data and the model hindcast, a connection between the decadally modulated recirculation gyre, the upstream KE path, and the regional mesoscale eddy activity is finally sought by focusing on the migration of the KE jet inflow over the Izu-Ogasawara Ridge.

\section{Sea surface height data}

Satellite altimetry data are used in this study to capture the time-varying surface dynamic signals. Specifically, we use the global SSH anomaly dataset compiled 
by the CLS Space Oceanographic Division of Toulouse, France. The dataset merges the Ocean Topography Experiment (TOPEX)/Poseidon, Jason-1, and European Remote Sensing Satellite ERS-1/2 along-track SSH measurements and has a much improved capability of detecting the mesoscale SSH signals (Le Traon and Dibarboure 1999; Ducet et al. 2000). The CLS SSH dataset used in this study has a 7-day temporal resolution and a $1 / 3^{\circ} \times 1 / 3^{\circ}$ spatial resolution and covers the period from October 1992 to December 2004.

In a midlatitude western boundary current outflow region such as the KE, part of the altimetrically measured SSH anomaly signals reflects the seasonally varying surface heat flux forcing that causes expansion or contraction of the water column (e.g., Stammer 1997; Gilson et al. 1998). As these steric height changes are not of interest to this study, they are removed from the weekly SSH anomaly dataset by using the surface heat flux product from the National Centers for Environmental Prediction (NCEP) reanalysis (Kalnay et al. 1996). ${ }^{1}$ Once the SSH anomaly field $h^{\prime}(x, y, t)$ is determined, the total SSH field $h(x, y, t)$ is simply the sum of the climatological SSH field $\bar{h}(x, y)$ (see Fig. 1) and the anomaly field: $h=\bar{h}+h^{\prime}$. For brevity, the total SSH field will be referred to simply as the SSH field below.

\section{Low-frequency changes in the KE system}

To explore the low-frequency changes in the KE jet and its surrounding areas, we start with Fig. 2 showing the annually averaged SSH fields for the past $12 \mathrm{yr}$. In 1993/94, the averaged SSH field had a spatial pattern very similar to the climatological SSH field (cf. Fig. 1): the two quasi-stationary meanders were well-developed and so was the southern recirculation gyre. This closeto-climatology SSH pattern, however, started to degenerate during 1995-96, and by 1997 the averaged SSH pattern had almost no resemblance to that of the climatology: both the quasi-stationary meanders and the southern recirculation gyre are barely discernible. From 2000 to 2001, the quasi-stationary meanders can be seen to reemerge and the southern recirculation gyre to restrengthen. In 2002-04, the averaged SSH shows

\footnotetext{
${ }^{1}$ Using the surface meteorological data measured by a Japan Meteorological Agency buoy at $29^{\circ} \mathrm{N}, 135^{\circ} \mathrm{E}$, we recently carried out an in-depth comparison between the daily NCEP air-sea flux product and the buoy estimate (Qiu et al. 2004). The rms amplitude of the NCEP net heat flux was found to be biased high by $23 \%$. Despite this amplitude bias, however, the NCEP product captures the timing and relative strength of the synoptic-scale net heat flux forcing very well. Based on this finding, the magnitude of the NCEP heat flux data used in this study is scaled down by $18.7 \%$.
}

again a spatial pattern very similar to that of the climatology. While similar in pattern, it is important to emphasize that the mean KE jet in 2003/04 is 2 times as strong as the climatological KE jet (e.g., the SSH difference across the first meander of the KE jet is $1.4 \mathrm{~m}$ in 2003/04 in Fig. 2 as compared with 0.7 m in Fig. 1).

The low-frequency changes just described can also be seen in Fig. 3 in which we superimposed snapshots of the KE paths in individual years. Here, the paths of the KE jet are defined by the 170-cm SSH contours in the SSH maps. As indicated by the thick black lines in Fig. 2, the 170-cm SSH contours are consistently located at, or near, the $\partial h / \partial y$ maxima and are a good indicator for the KE jet axis. As may be expected, the KE path tends to be more variable during the period when the quasistationary meanders are obscure in the averaged SSH maps (e.g., 1996-99) than when the quasi-stationary meanders are well-defined in the average. Indeed, the most stable path of the KE jet is seen in 2002-04 when the quasi-stationary meanders and the southern recirculation gyre are most fully developed.

To further understand the variability shown in Figs. 2 and 3, we will divide our analyses below into four geographical regions that encompass the KE system.

\section{a. Upstream KE jet $\left(141^{\circ}-153^{\circ} \mathrm{E}\right)$}

As we noted in the introduction, the KE jet in this upstream region is characterized by the presence of two quasi-stationary meanders. Using the weekly SSH data, we plot in Fig. 4a the time series of the path length of the KE jet integrated in this region. Note that a straight zonal path in the region would have a length of $1090 \mathrm{~km}$ and a larger value in Fig. 4a indicates a more convoluted path taken by the KE jet. It is clear from the time series that the upstream KE jet in the last decade had two distinct modes: a stable mode in which the KE jet had a short path accompanied by weak temporal variability, and an unstable mode in which the KE path was convoluted and exhibited monthly time-scale fluctuations resulting from the shedding and merging of mesoscale eddies. The stable mode of the upstream KE jet existed before May 1995 and after January 2002, whereas the unstable mode persisted from mid 1995 to the end of 2001.

A look into the eddy kinetic energy level in the upstream KE region $\left(32^{\circ}-38^{\circ} \mathrm{N}\right.$ and $\left.141^{\circ}-153^{\circ} \mathrm{E}\right)$ reveals that its variability correlates well the regional KE path variability. As shown in Fig. 4b, the eddy kinetic energy level tends to be higher when the upstream KE path is more convoluted and vice versa. Notice that because the "mean" KE jet also modulates with time (e.g., Fig. 2 ), the eddy kinetic energy is calculated here based on 

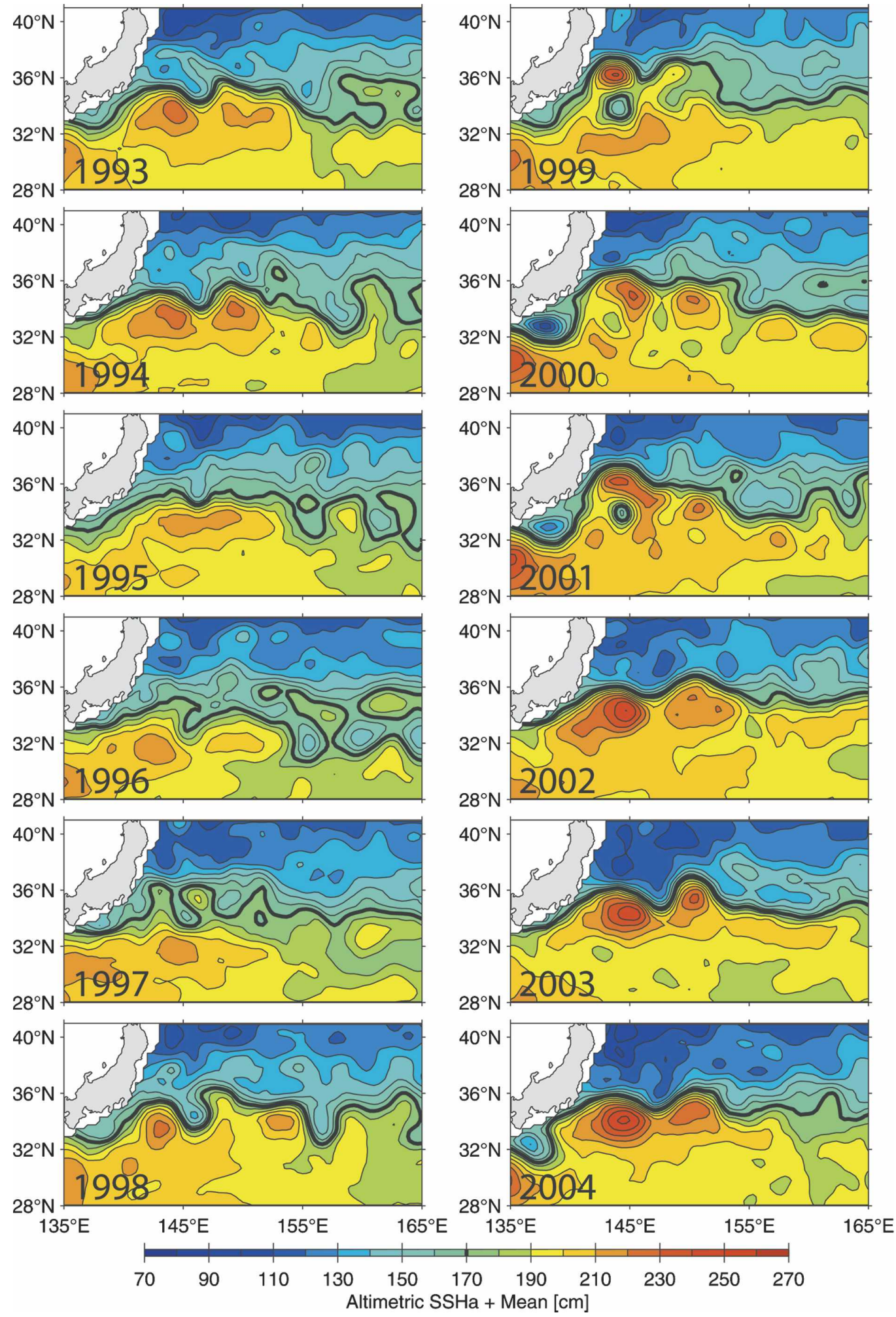

FIG. 2. Maps of yearly averaged sea surface height field. Contour intervals are $10 \mathrm{~cm}$ with the thick lines denoting the $170-\mathrm{cm}$ contours. 

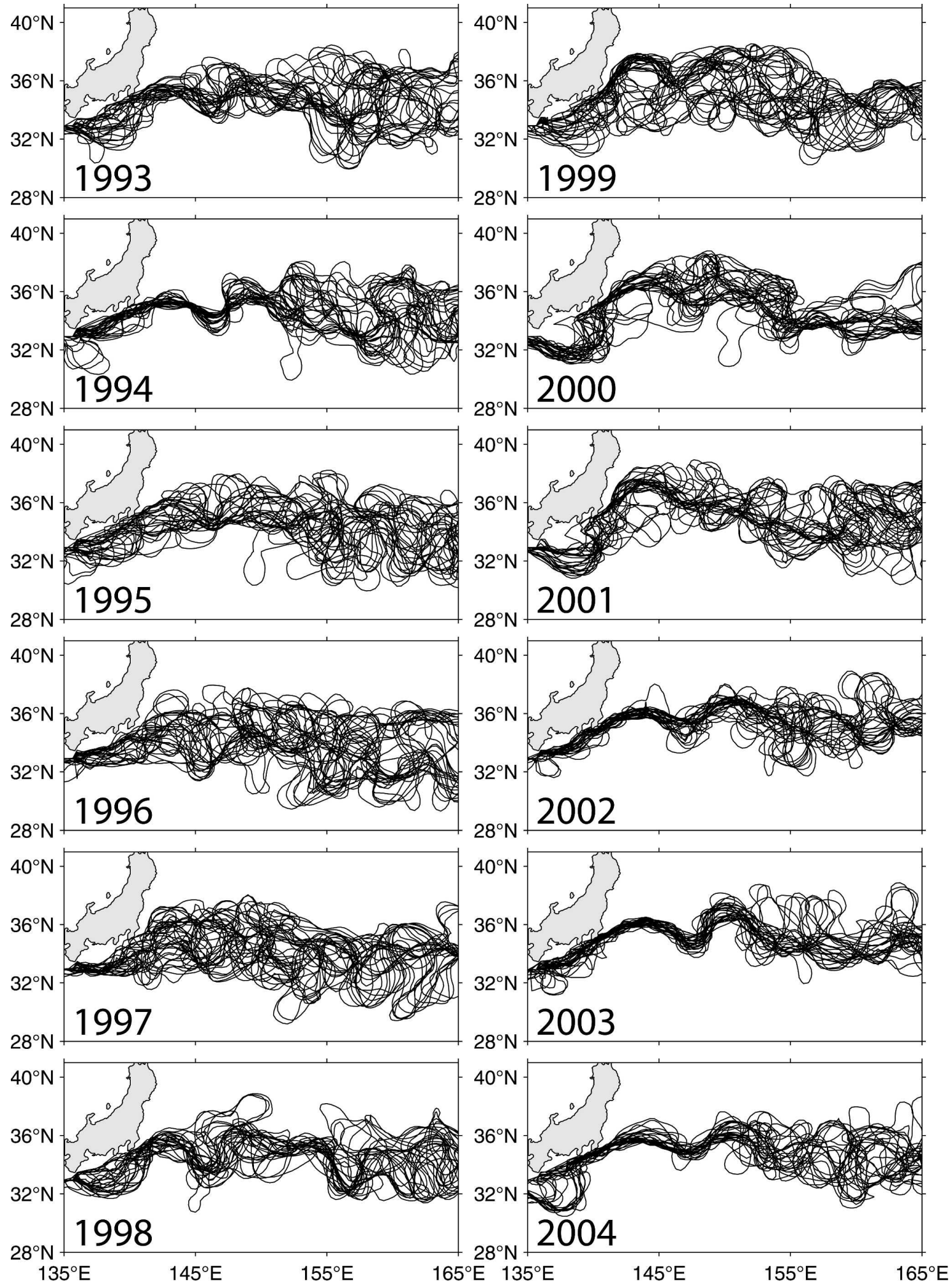

FIG. 3. Yearly paths of the Kuroshio and Kuroshio Extension defined by the 170-cm contours in the weekly SSH fields. Here paths are plotted every 14 days. 
(a) Upstream KE Path Length $\left(141^{\circ}-153^{\circ} \mathrm{E}\right)$
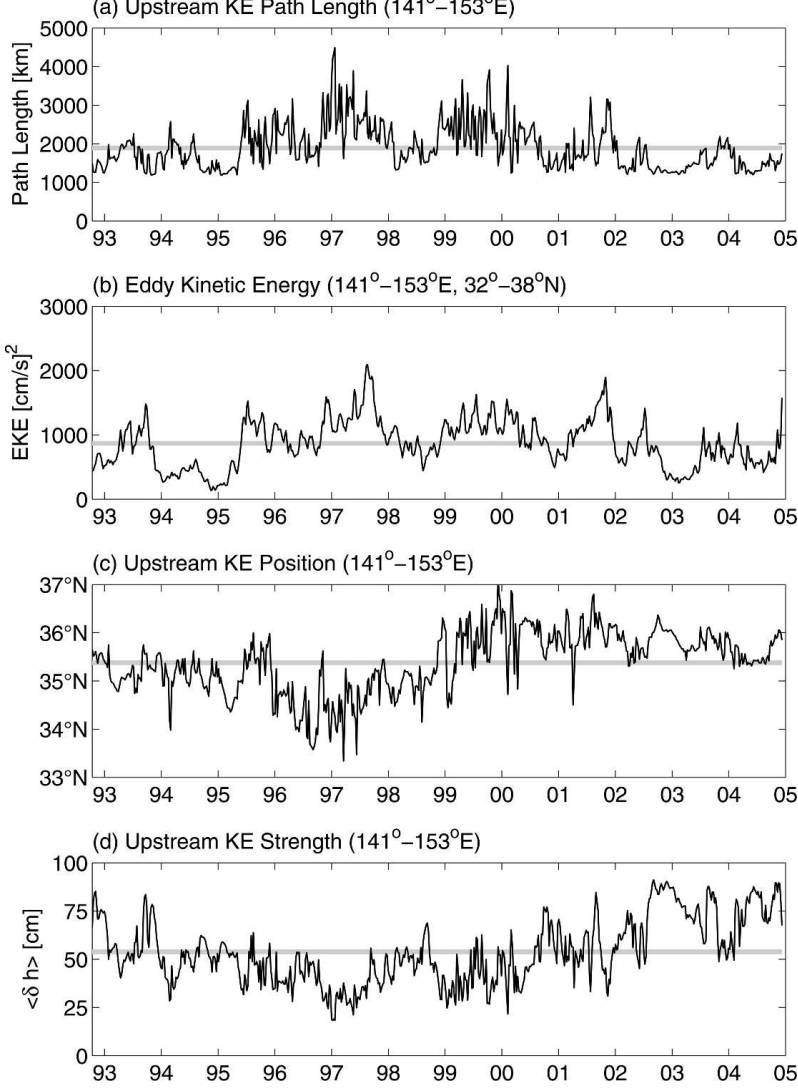

FIG. 4. (a) Upstream KE path length integrated from $141^{\circ}$ to $153^{\circ} \mathrm{E}$. (b) Eddy kinetic energy in the upstream $\mathrm{KE}$ region of $32^{\circ}-38^{\circ} \mathrm{N}$ and $141^{\circ}-153^{\circ} \mathrm{E}$. (c) Latitudinal position of the KE averaged from $141^{\circ}$ to $153^{\circ} \mathrm{E}$. (d) $\mathrm{SSH}$ difference across the KE jet averaged from $141^{\circ}$ to $153^{\circ} \mathrm{E}$. Gray lines denote the mean values of the quantity over the period of analysis.

the high-pass filtered SSH anomaly data with time scales shorter than 300 days.

Figure $4 \mathrm{c}$ shows the time series of the mean latitudinal position of the KE jet averaged in the upstream region. Aside from the monthly time-scale signals induced by mesoscale eddies, the time series reveals a clear decadal modulation, with the zonal-mean KE jet located near $35.5^{\circ} \mathrm{N}$ in $1993 / 94$, migrating southward in 1996-97, shifting northward in 1998-99, and returning to its climatological latitude of $35.5^{\circ} \mathrm{N}$ in $2003-04$.

Decadal modulation is also clear in Fig. 4d, which shows the time series of the SSH difference $\langle\delta h\rangle$ across the KE jet averaged from $141^{\circ}$ to $153^{\circ} \mathrm{E}$. Here, $\delta h$ is evaluated at each longitude by first averaging the SSH values over the $1.5^{\circ}$ bins centered $1^{\circ}$ north and south of the KE's axis $\left(h_{N}\right.$ and $\left.h_{S}\right)$, and then taking the difference $\delta h=h_{S}-h_{N}$. From geostrophy, $\langle\delta h\rangle$ gives a measure of the mean strength of the upstream KE jet. Consistent with the yearly SSH maps of Fig. 2, the upstream KE jet was strong in 1992-93 and had a decreasing trend in strength from 1994 to 1997. This trend reversed after 1998 and the upstream KE jet increased its strength to the level of 1992-93 in recent years.

\section{b. Downstream KE jet $\left(153^{\circ}-165^{\circ} \mathrm{E}\right)$}

The KE jet downstream of $153^{\circ} \mathrm{E}$ is in general more variable than its upstream counterpart both because it is farther away from the coastal boundary and because the jet here has to negotiate with the presence of the Shatsky Rise (see Fig. 1). Similar to Fig. 4, we plot in Fig. 5a the time series of the KE path length integrated from $153^{\circ}$ to $165^{\circ} \mathrm{E}$. Interestingly, the downstream KE path shows a time evolution different from that of Fig. 4a: the KE path was long during 1993-97 and remained relatively short after 1998. Also unlike the upstream KE jet, Fig. 5b shows that the variability of the KE path length in the downstream region does not correlate well with the regional eddy kinetic energy signals. This lack of correlation is particularly obvious in 2001-04 during which an increase in the regional eddy kinetic energy level was not accompanied by the lengthening of the
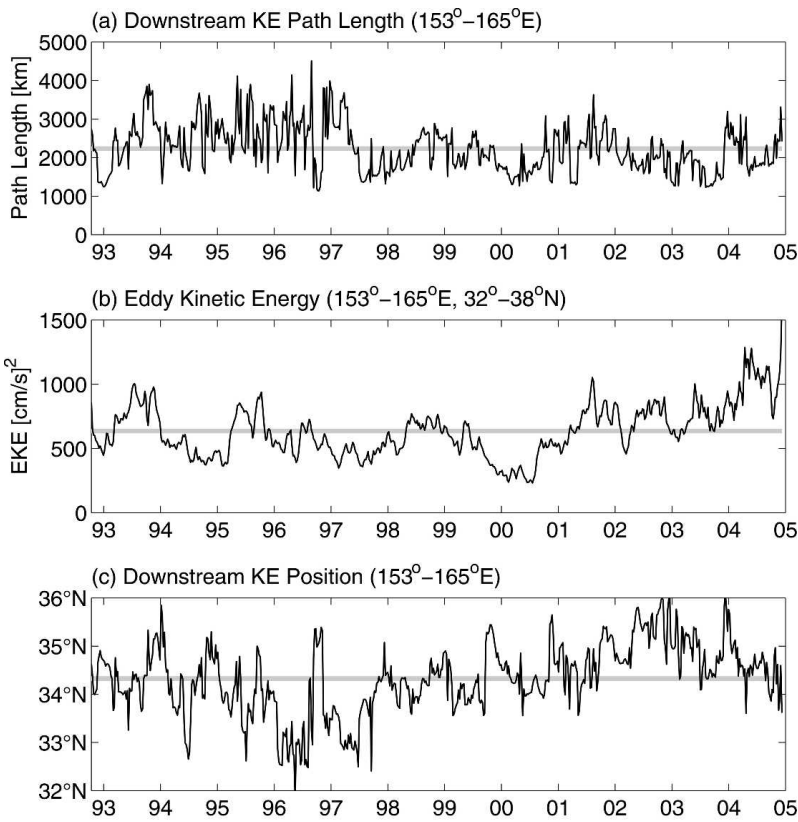

(d) Downstream KE Strength $\left(153^{\circ}-165^{\circ} \mathrm{E}\right)$

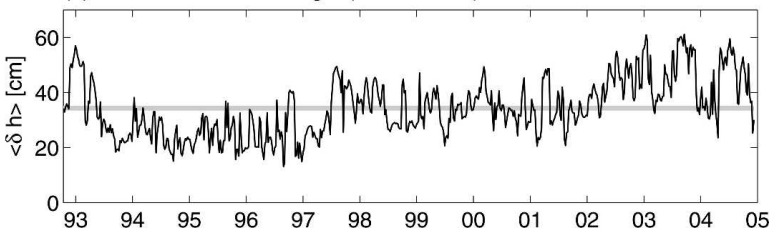

FIG. 5. Same as Fig. 4 but for the downstream KE jet $\left(153^{\circ}-165^{\circ} \mathrm{E}\right)$. 
KE path. Inspection of the sequential SSH maps (not shown) indicates that after 2001 the meandering KE jet in the downstream region tended to displace zonally, rather than meridionally. While elevating the regional eddy kinetic energy level, this east-west displacement of the meandering jet leads to no lengthening of the KE path.

Although temporally more variable, the zonal mean position of the downstream KE jet exhibits a decadal change quite similar to that of the upstream KE jet (cf. Figs. $4 \mathrm{c}$ and $5 \mathrm{c}$ ): the zonal mean jet position had a generally southward migration during 1994-97, but reversed the direction during 1997-2002. When compared with the time series of Fig. 4d, Fig. 5d shows a similar decadal trend in the strength of the downstream KE jet: the zonal-mean SSH difference $\langle\delta h\rangle$ was high in 199293, dropped to a low level during 1994-96, and rebounded after 2002 .

\section{c. Southern recirculation gyre}

From the basic dynamics of a western boundary current extension (e.g., Pedlosky 1996), one expects some of the low-frequency changes of the KE jet described above to be connected to the variability of the southern recirculation gyre. To quantify this connection, we focus in this subsection on the SSH signals in the region bounded to the east by the Shatsky Rise $\left(158^{\circ} \mathrm{E}\right.$; see Fig. 1), west by the Izu Ridge $\left(141^{\circ} \mathrm{E}\right)$, north by the KE jet, and south by the $30^{\circ} \mathrm{N}$ parallel. As depicted in Fig. 1 , this is the region nominally occupied by the southern recirculation gyre of the KE.

Figure $6 \mathrm{a}$ shows the time series of the recirculation gyre strength defined by

$$
S(t) \equiv \iint_{A} h(x, y, t) d x d y,
$$

where $A$ denotes the area within which the SSH value exceeds $2.0 \mathrm{~m}$ in the region of our interest. This threshold SSH value is chosen as it delineates well the outer boundaries of the southern recirculation gyre in individual SSH maps (see, e.g., Fig. 2). The time series of Fig. 6a bears a good resemblance to the time series of $\langle\delta h\rangle$ across the upstream KE jet (Fig. 4d). The linear correlation coefficient between the two time series is 0.68 (and it reaches 0.85 if the signals with annual and higher frequencies are removed from the time series). The favorable correspondence between Figs. 6a and 4d is of no surprise because the inflated eastward transport of the KE jet (as compared with the Sverdrup transport) is due to the existence of the anticyclonic recirculation gyre (Wijffels et al. 1998).

The close connection between the southern recircu-
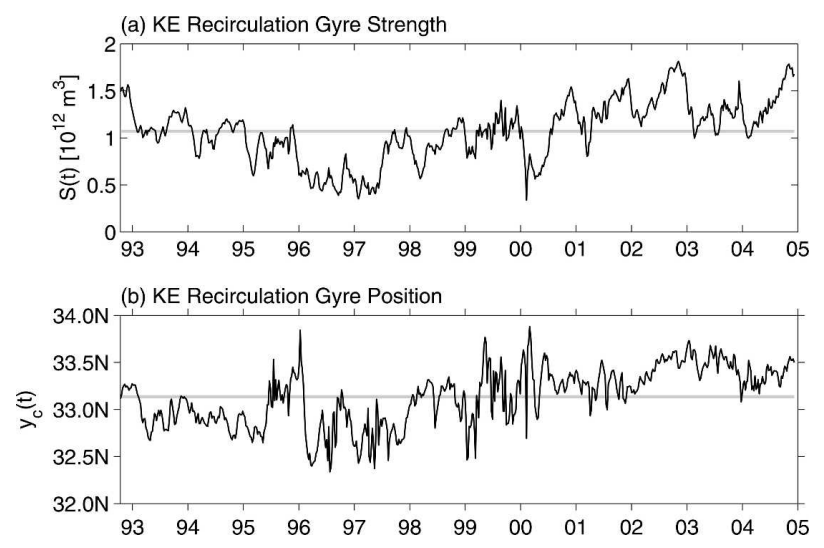

FIG. 6. (a) Strength of the KE recirculation gyre defined by Eq. (1). (b) Latitudinal position of the recirculation gyre defined by Eq. (2). Gray lines denote the mean values of the quantity over the period of analysis.

lation gyre and the upstream $\mathrm{KE}$ jet is also reflected in their covarying latitudinal movements. In Fig. 6b, we plot the time series for the latitudinal center of the southern recirculation gyre defined by

$$
y_{c}(t) \equiv \frac{1}{S(t)} \iint_{A} y h(x, y, t) d x d y .
$$

When compared with Fig. 4c, it is clear that a northward migration in the zonal mean upstream KE jet tends to be accompanied by a northward shift in the center of the southern recirculation gyre. The linear correlation coefficient between the time series of Figs. $4 \mathrm{c}$ and $6 \mathrm{~b}$ is 0.67 and it increases to 0.88 if the time series are low-pass filtered to retain only the interannual signals.

\section{d. Kuroshio south of Japan}

Constrained by the coast of Japan to the north, the Tokara Strait to the west, and the Izu Ridge to the east, the Kuroshio south of Japan is well known for its bimodal path fluctuations on interannual-to-decadal time scales (for a comprehensive review regarding the observations and dynamics of the Kuroshio path bimodality, readers are referred to Qiu and Miao 2000). Is the KE variability described above, in any way, influenced by the Kuroshio path changes south of Japan?

To capture the Kuroshio variability south of Japan, we plot in Fig. 7a the time series of the mean Kuroshio position averaged from $135^{\circ}$ to $140^{\circ} \mathrm{E}$. While exhibiting frequent large-amplitude offshore excursions, the Kuroshio path in the last $12 \mathrm{yr}$ has remained largely in a near-shore straight mode (Kawabe 1995). The exceptions were during 2000-01, in which a relatively stable "large meander path" persisted for about $2 \mathrm{yr}$, and after July 2004. A look at Fig. 2e indicates that 2000-01 are 
(a) Kuroshio Position South of Japan $\left(135^{\circ}-140^{\circ} \mathrm{E}\right)$

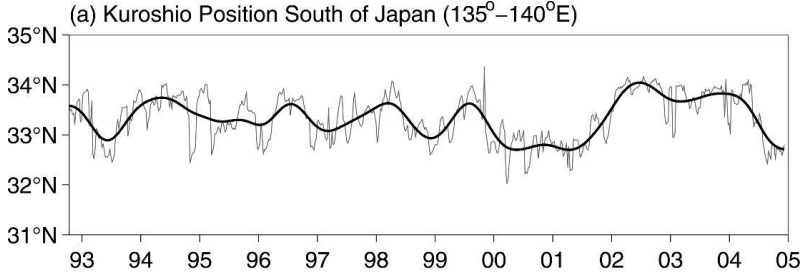

(b) Upstream KE Position $\left(141^{\circ}-153^{\circ} \mathrm{E}\right)$

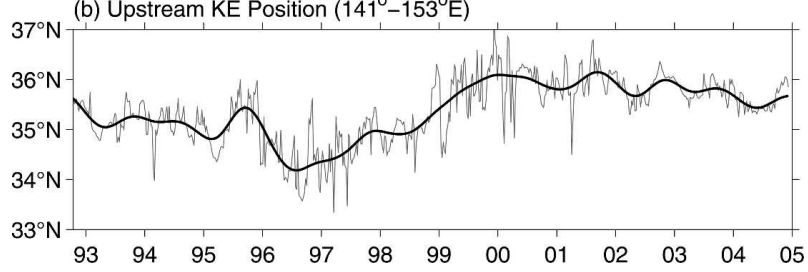

FIG. 7. (a) Latitudinal position of the Kuroshio path averaged from $135^{\circ}$ to $140^{\circ} \mathrm{E}$ south of Japan. (b) Latitudinal position of the $\mathrm{KE}$ averaged from $141^{\circ}$ to $153^{\circ} \mathrm{E}$, as in Fig. 4c. In both panels, thin lines denote the time series based on the weekly SSH data and thick lines denote the low-pass-filtered time series after removing signals with time scales shorter than 300 days.

the years when the upstream KE jet has a more-thannormal northerly path. However, as shown in Fig. 7b (same as Fig. 4c), the northward shift of the upstream KE jet started in late 1998, a year before the Kuroshio south of Japan transitioned from a straight path to a meandering path. Given the results presented in Fig. 7, it is more natural to conclude that the gradual northward shift of the upstream KE jet after late 1998 is due to the strengthening of the south recirculation gyre and its northward migration than that it is associated with the meandering of the Kuroshio south of Japan in 2000-01.

\section{Mechanism for the decadal recirculation gyre modulation}

Results of the preceding section point clearly to the importance of the southern recirculation gyre in understanding the low-frequency changes of the KE jet. Dynamically, fluctuations in the recirculation gyre can result from eddy-mean flow interaction, eddy-eddy interaction, and forced thermocline variability due to surface wind forcing. In this section, we will explore the roles played by the latter process. Located near the western boundary of the North Pacific basin, the KE and its recirculation regions are where wind-forced thermocline responses ultimately accumulate (Miller et al. 1998; Deser et al. 1999; Seager et al. 2001; Schneider et al. 2002; Qiu 2003). To what extent can the decadal variability observed in the recirculation gyre be explained by the forcing of the large-scale wind stress field?
To address this question, it is useful to adopt a $1 \frac{1}{2}-$ layer reduced-gravity model that governs the baroclinic ocean response to surface wind forcing. Under the long-wave approximation, the linear vorticity equation of the model is

$$
\frac{\partial h}{\partial t}-c_{R} \frac{\partial h}{\partial x}=-\frac{g^{\prime} \operatorname{curl} \tau}{\rho_{o} g f},
$$

where $h$ is the SSH of interest, $c_{R}$ is the speed of the long baroclinic Rossby waves, $g^{\prime}$ is the reduced gravity, $\rho_{o}$ is the reference density, $f$ is the Coriolis parameter, and $\tau$ is the wind stress vector. Integrating Eq. (3) from the eastern boundary $\left(x_{e}\right)$ along the baroclinic Rossby wave characteristic leads to

$$
\begin{aligned}
h(x, y, t)= & h\left(x_{e}, y, t+\frac{x-x_{e}}{c_{R}}\right) \\
& +\frac{g^{\prime}}{\rho_{0} g f c_{R}} \int_{x_{e}}^{x} \operatorname{curl} \tau\left(x^{\prime}, y, t+\frac{x-x^{\prime}}{c_{R}}\right) d x^{\prime} .
\end{aligned}
$$

Using Eq. (4) and the monthly wind stress data from the NCEP reanalysis (Kalnay et al. 1996), Qiu (2003) hindcast the SSH anomaly field for the midlatitude North Pacific. For the region surrounding the KE, he found that the linear vorticity model was able to reproduce the large-scale, low-frequency SSH changes favorably (for details, see Figs. 8 and 9 in Qiu 2003). In this study we extend the hindcast for the SSH anomaly field, using the same wind dataset and physical parameters. Figure 8a shows the modeled SSH anomalies averaged over the latitudinal band of the KE recirculation gyre, $32^{\circ}-34^{\circ} \mathrm{N}$, as a function of time and longitude. For comparison, the same $x-t$ plot for the SSH anomalies from the altimetric measurements is shown in Fig. 8b. In both plots, the SSH values in the KE recirculation gyre region of $140^{\circ}-160^{\circ} \mathrm{E}$ are dominated by positive anomalies in 1993-94. From 1995 to 2000, negative SSH anomalies can be seen to expand from the east, replacing the earlier positive SSH anomalies in the recirculation gyre region. This arrival of negative $\mathrm{SSH}$ anomalies corresponds to the weakening of the recirculation gyre from 1996 to 2000. After 2001, the same process, but with the oppositely signed $\mathrm{SSH}$ anomalies, took place. The strengthening of the recirculation gyre seen in recent years is related to these positive SSH anomalies propagated from the east. It is interesting to note that in 2004 negative SSH anomalies start to emerge in the downstream recirculation gyre region. This signals the possibility of a weakening of the recirculation gyre in the coming years. 


\section{(a) Model SSH anomaly}

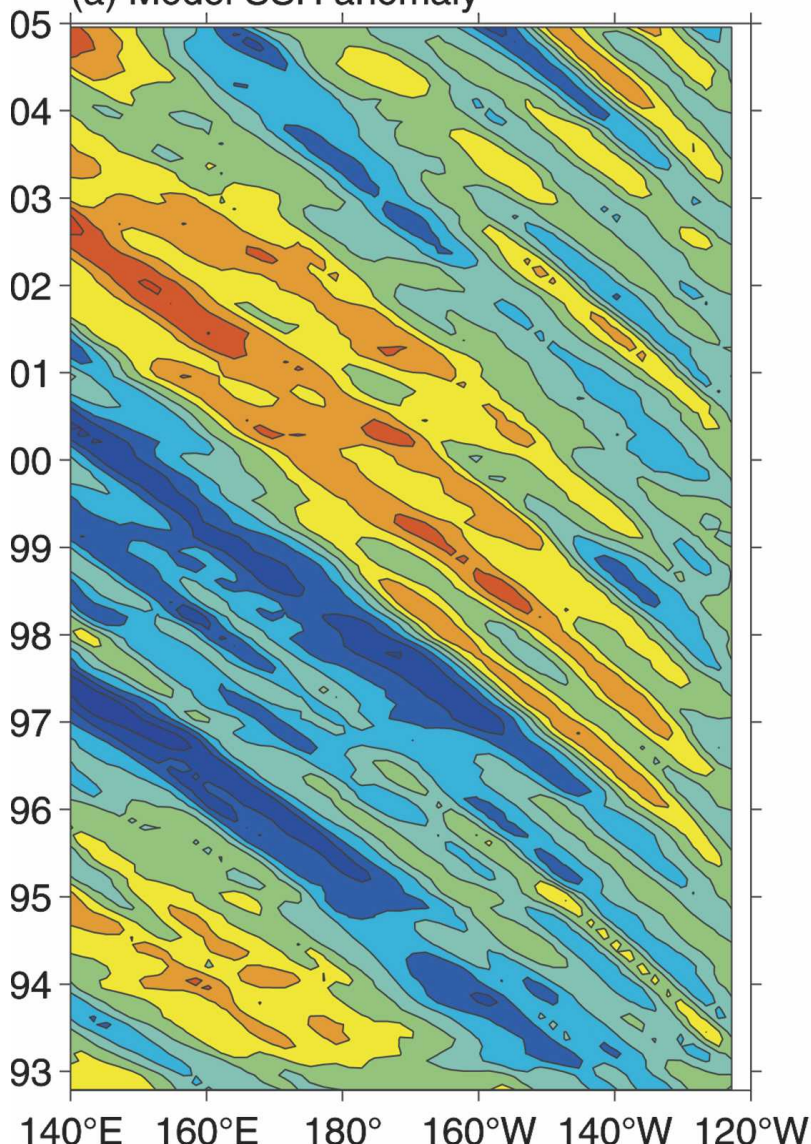

\section{(b) Altimetry SSH anomaly}

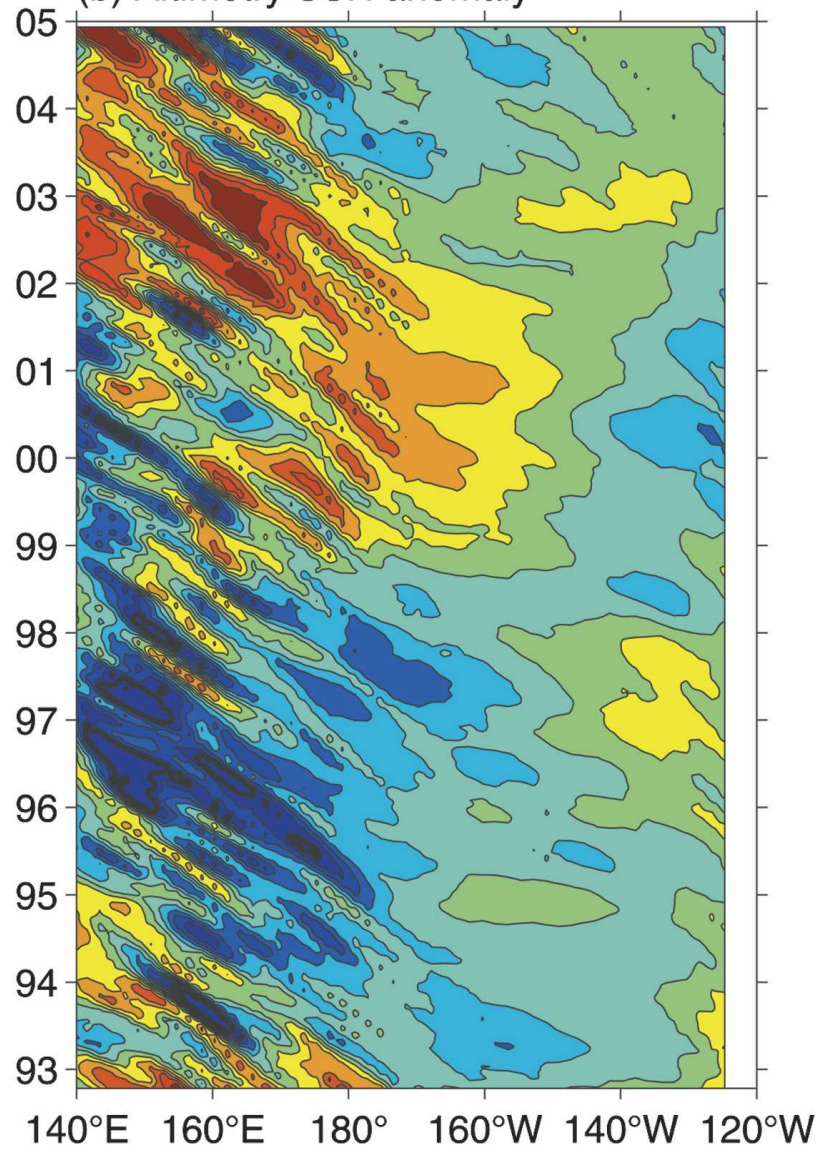

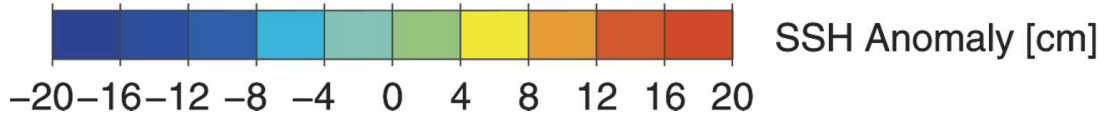

FIG. 8. SSH anomalies along the zonal band of $32^{\circ}-34^{\circ} \mathrm{N}$ from (a) the linear vorticity model and (b) the satellite altimetric data.

Notice that most of the low-frequency SSH signals originate near $160^{\circ} \mathrm{W}$ in the eastern North Pacific. As detailed in Qiu (2003, his Fig. 2), this is the region where the large-scale wind stress curl forcing associated with the Pacific decadal oscillation (PDO) has its largest amplitude. For example, the negative SSH anomalies generated around $160^{\circ} \mathrm{W}$ in recent years are due to the curl $\tau>0$ forcing associated with the positive phase of the PDO after mid-2002 (Mantua et al. 1997).

By adding the modeled SSH anomalies to the mean SSH data of Teague et al. (1990), we compare in Fig. 9 the biennially averaged SSH fields from the linear vorticity model with the altimetry observations. The decadal modulation of the recirculation gyre can be discerned in both the model output (Fig. 9a) and the observations (Fig. 9b): strong before 1995, weakening in subsequent years, and restrengthening after 2000.
While the model captures the modulating trends of the recirculation gyre, it is clear from Fig. 9 that it underestimates the strength of the recirculation gyre. This model deficiency is further quantified in Fig. 10 in which we compare the time series of the recirculation gyre strength based on observations with that based on the model. The overall strength of the recirculation gyre in the model is about $62 \%$ of that in the observations, implying that the dynamic processes neglected in the linear vorticity model can have a rectified effect in strengthening the recirculation gyre. Interestingly, the largest discrepancy between the modeled and observed strength of the recirculation gyre in Fig. 10 appears during 1996-99, the period when the upstream KE jet had an unstable path and when the regional eddy kinetic energy level was higher than normal (recall Figs. $4 a, b)$. Evidence for such a rectified effect due to the 
(a) Model SSH
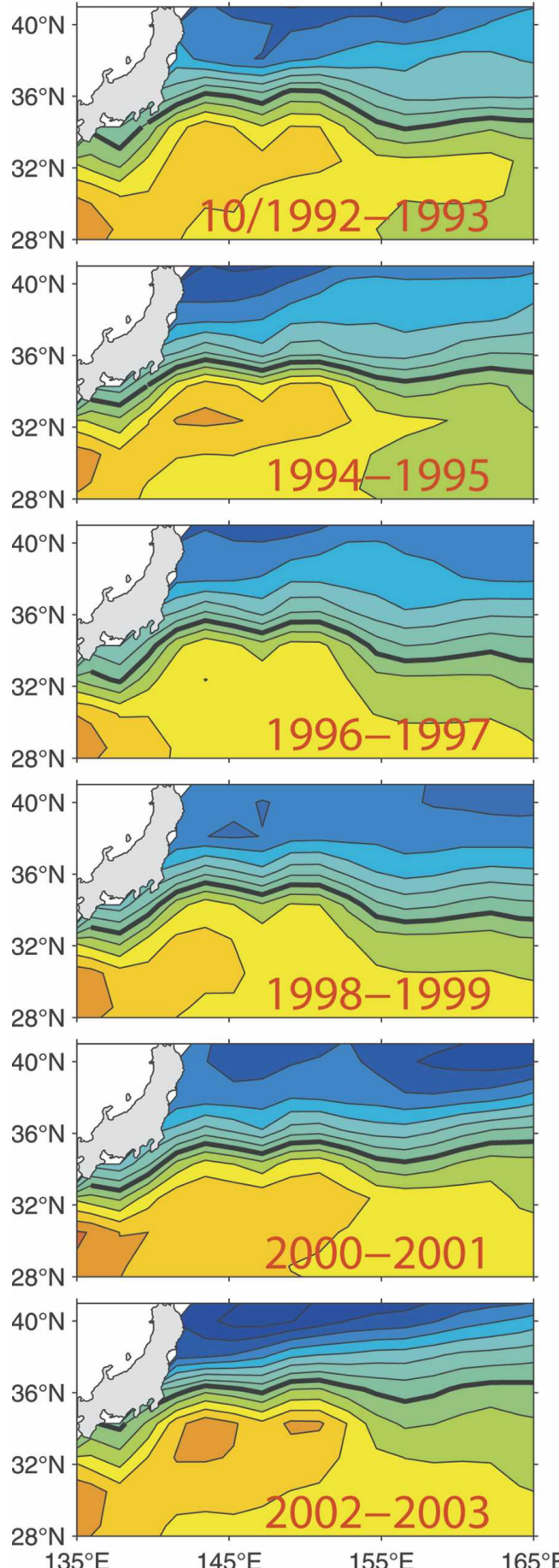

$135^{\circ} \mathrm{E}$ (b) Altimetry SSH
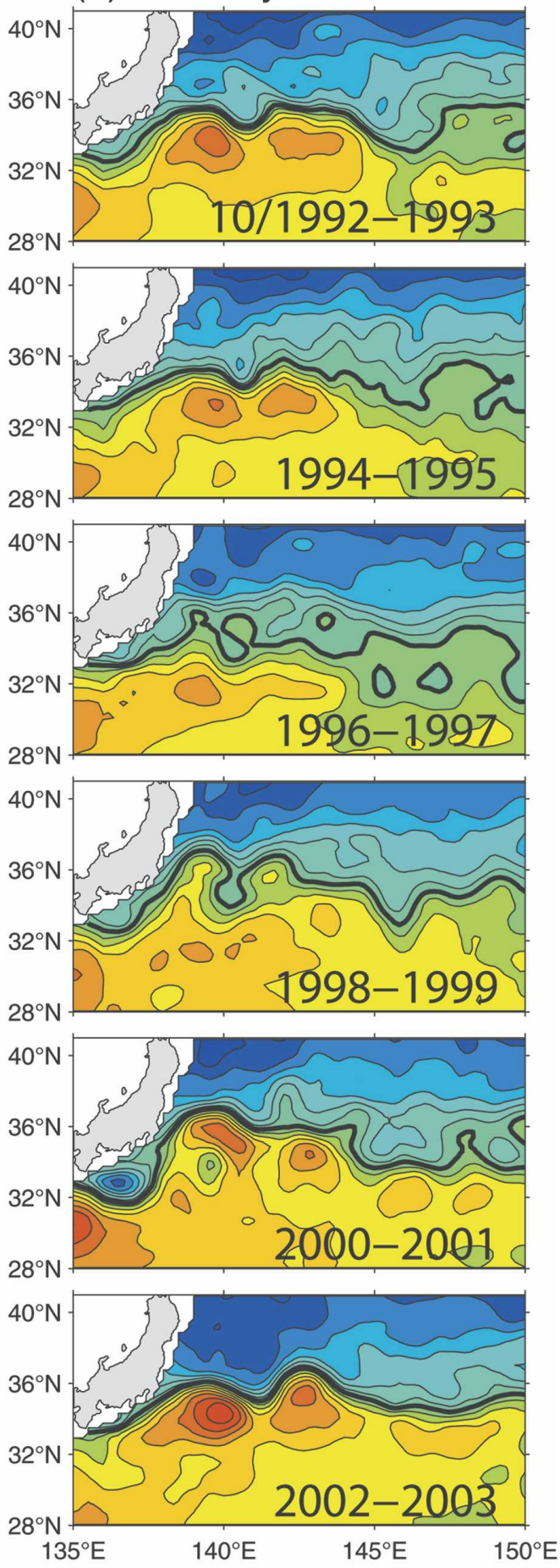

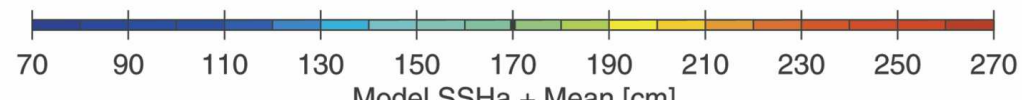

Model SSHa + Mean [cm]

FIG. 9. Biennially averaged SSH fields with the SSH anomalies (a) hindcast by the linear vorticity model and (b) observed by the satellite altimeters. As in Fig. 2, the mean SSH field is based on Teague et al. (1990) and thick lines denote the $170-\mathrm{cm}$ contours. 


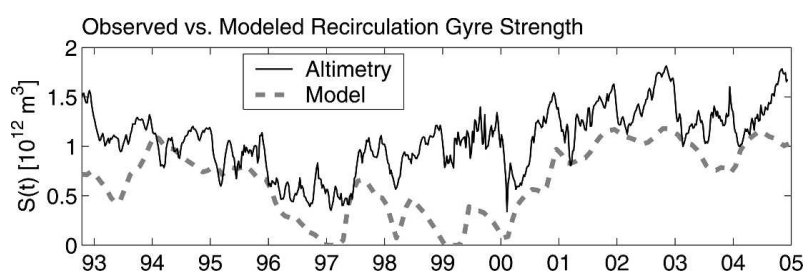

FIG. 10. Strength of the recirculation gyre derived from the linear vorticity model (dashed line) and from the altimetry observations (solid line; same as in Fig. 6a). Definition for the recirculation gyre strength is given by Eq. (1).

eddy-mean flow interaction can be found in a recent high-resolution general circulation model study by Taguchi et al. (2005).

\section{Bimodal state and the Izu-Ogasawara Ridge}

One interesting result obtained from the data analyses in section 3 is that when the KE jet and recirculation gyre were in a weaker (stronger) state, the upstream KE path tended to become more (less) variable and the regional eddy kinetic energy level tended to be higher (lower). This relationship between the strength of the $\mathrm{KE}$ jet/recirculation gyre and the regional eddy kinetic energy level is rather counterintuitive, because stability analysis commonly suggests that a stronger mean flow would favor baroclinic instability and lead to more vigorous eddy generation. Clearly, baroclinic instability is not the dominant mechanism controlling the modulating mesoscale eddy field of the observed KE system.

A careful look at the time-varying SSH maps reveals that the state of the upstream KE jet/recirculation gyre is closely connected to the latitudinal position of the KE jet inflow as it crossed the Izu-Ogasawara Ridge (see Fig. 11 for the regional detailed bathymetry). When the inflow jet was observed to be located close to the Japan coast before 1995 and after 2002, the upstream KE path tended to be in a stable mode (see Figs. 12a versus 12b). On the other hand, from 1996 to 2001 when the upstream KE path was observed to be unstable, the inflow KE jet had wandered southward over the shallower segment of the Izu-Ogasawara Ridge between $32^{\circ}-34^{\circ} \mathrm{N}$ (depth $\left.<1 \mathrm{~km}\right)$. The fact that the KE jet east of the Izu-Ogasawara Ridge should develop large amplitude meanders when it overrides the shallow ridge can be expected from the conservation of potential vorticity (e.g., Toba and Murakami 1998).

What, then, caused the KE jet inflow along the IzuOgasawara Ridge to deflect southward during 19962001? To answer this question, we plot in Fig. 12c the $\mathrm{KE}$ jet position along the eastern flank of the Izu-
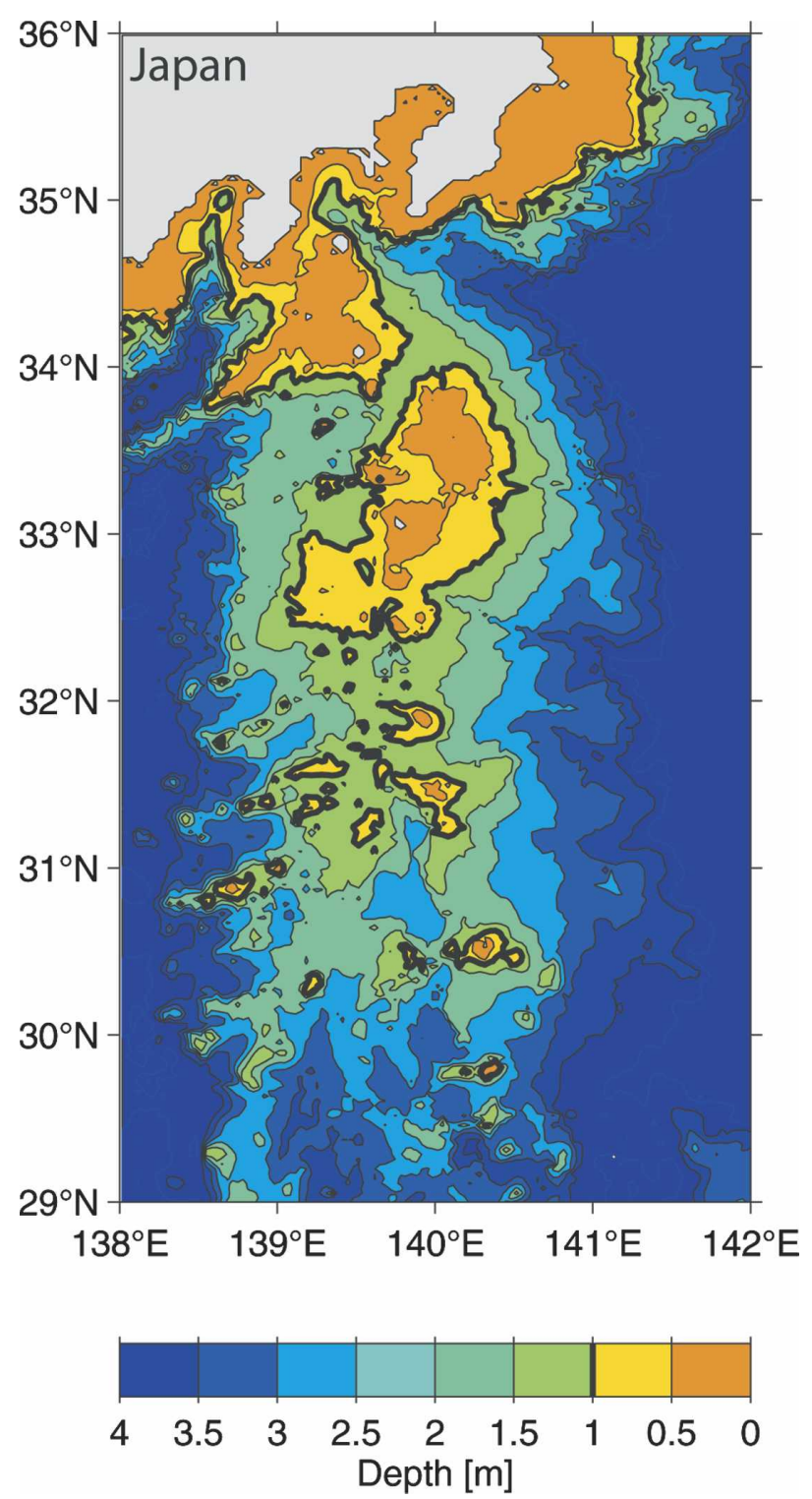

FIG. 11. Bathymetry around Izu-Ogasawara Ridge based on Smith and Sandwell (1994). Thick contours denote the 1000-m isobaths.

Ogasawara Ridge hindcast by the linear vorticity model. The good correspondence between this time series and Fig. 12a indicates that the observed southward deflection of the KE jet during 1996-2000 is likely caused by the arrival of the negative SSH anomalies from the east and the resultant weakening of the recirculation gyre (see Fig. 9a for the modeled paths of the $\mathrm{KE}$ jet inflow around the Izu-Ogasawara Ridge). In contrast, arrival of the positive SSH anomalies at the Izu-Ogasawara Ridge in recent years forced the inflow KE path to flow against the Japan coast. By passing through the deep channel of the Izu-Ogasawara Ridge 
(a) KE Position along the Eastern Flank of the Izu Ridge

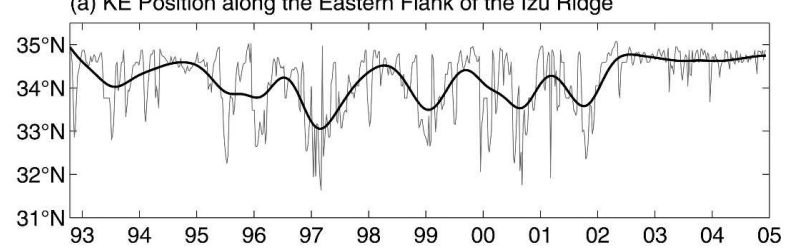

(b) Upstream KE Path Length $\left(141^{\circ}-153^{\circ} \mathrm{E}\right)$

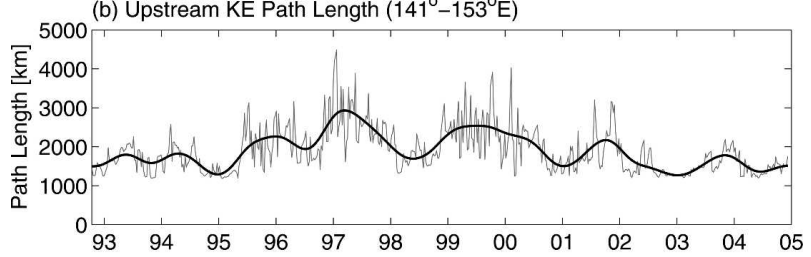

(c) Modeled KE Position along the Eastern Flank of the Izu Ridge

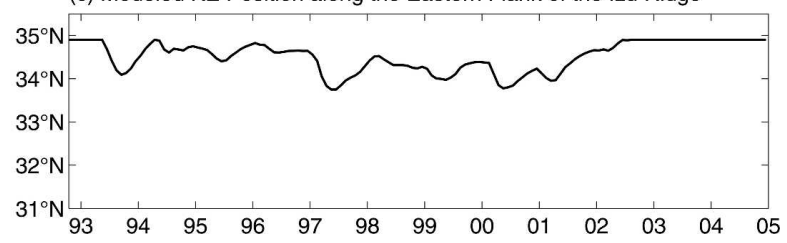

FIG. 12. (a) Latitudinal position of the KE along the eastern flank of the Izu-Ogasawara Ridge ( $\sim 140^{\circ} \mathrm{E}$; see Fig. 1). (b) Upstream KE pathlength integrated from $141^{\circ}$ to $153^{\circ} \mathrm{E}$ (same as in Fig. 4a). (c) Same as in (a) except for the result hindcast by the linear vorticity equation. In (a) and (b), thin lines denote the time series based on the weekly SSH data and thick lines denote the low-pass filtered time series after removing signals with time scales shorter than 300 days.

near $34^{\circ} \mathrm{N}$ (see Fig. 11), and possibly with the aid of a strengthened recirculation gyre, the upstream KE jet was able to stabilize after 2002.

\section{Summary}

Using the sea surface height data derived from the multiple satellite altimeters of the past $12 \mathrm{yr}$, we investigated in this study the low-frequency changes in the $\mathrm{KE}$ jet, the southern recirculation gyre, and their mesoscale eddy field. The dominant signal has a decadal time scale and is characterized by a gradual weakening of the upstream $\mathrm{KE}$ jet $\left(141^{\circ}-153^{\circ} \mathrm{E}\right)$ from late 1992 to 1996 and a subsequent, steady strengthening of the jet following 1997. The same decadal modulation is seen in the strength of the recirculation gyre and, to a lesser degree, in the intensity of the downstream $\mathrm{KE}$ jet $\left(153^{\circ}-165^{\circ} \mathrm{E}\right)$. During the weakening period of 1993-96, the path of the KE jet is seen to have migrated progressively southward, whereas during the strengthening period after 1997, the path tended to shift northward. The meridional path change of the KE jet is related closely to the modulation in the strength/ position of the southern recirculation gyre; it is inde- pendent of the bimodal Kuroshio path variability south of Japan.

To explore the dynamics underlying the observed modulation of the $\mathrm{KE}$ jet and recirculation gyre, we examined the baroclinic ocean responses under realistic surface wind forcing. By adopting a reduced-gravity model with linear vorticity dynamics, we showed that the observed weakening trend of 1993-96 was due to the westward propagation of negative $\mathrm{SSH}$ anomalies that caused a gradual drop in SSH difference across the $\mathrm{KE}$ jet. Westward propagation of positive SSH anomalies after 1997, on the other hand, increased the meridional SSH difference progressively, leading to the strengthening of the KE jet and the recirculation gyre. The observed, as well as the modeled, westwardexpanding positive and negative $\mathrm{SSH}$ anomalies are generated by the wind stress curl anomalies at different phases of the Pacific decadal oscillation in the eastern North Pacific.

Decadal modulations also appear in the mesoscale eddy field of the KE jet/recirculation gyre. When the $\mathrm{KE}$ jet and recirculation gyre are in a weaker state, the upstream KE path tends to become more variable and the regional eddy kinetic energy level tends to be higher. In contrast, when the KE jet and recirculation gyre are stronger, the upstream KE path tends to exhibit stabilized stationary meanders, lowering the eddy kinetic energy level in the region. This negative relationship between the strength of the KE jet/recirculation gyre and the regional eddy kinetic energy level is likely due to the interaction of the inflow KE jet with the Izu-Ogasawara Ridge. As the recirculation gyre is weakened by the incoming negative $\mathrm{SSH}$ anomalies, both the SSH data and the linear vorticity model indicate that the inflow KE jet over the ridge tends to be shifted southward. By overriding the shallow segment of the ridge, the $\mathrm{KE}$ jet becomes destabilized in its downstream region. A strengthened recirculation gyre, on the other hand, works to anchor the KE jet inflow against the Japan coast. By passing through the deep passage in the Izu-Ogasawara Ridge, the upstream KE jet is able to remain in a quasi-stationary meandering pattern.

Last, we note that while the linear vorticity model was able to simulate well the decadal trends in the recirculation gyre, it is less successful in capturing the strength of the observed recirculation gyre. To what extent the westward impinging SSH anomalies can modify nonlinearly the pre-existing mean flow field and whether the enhanced mesoscale eddy activity is able to feedback to affect the KE jet and the recirculation gyre are some of the issues that need to be addressed in future observational and modeling studies. 
Acknowledgments. This study benefited from fruitful discussions with Ted Durland, Peter Hacker, Nikolai Maximenko, and Niklas Schneider. Detailed comments made by the anonymous reviewers and Lynne Talley helped improve an early version of the manuscript. The surface wind stress and heat flux data were generously provided by the National Centers for Environmental Prediction and the merged TOPEX/Poseidon, Jason-1, and ERS-1/2 altimeter data by the CLS Space Oceanography Division as part of the Environment and Climate EU ENACT project. This study was supported by NASA through Contracts 1207881 and 1228847.

\section{REFERENCES}

Adamec, D., 2000: Eddy flow characteristics and mean flow interactions in the North Pacific. J. Geophys. Res., 105, 11373 11383.

Aoki, S., S. Imawaki, and K. Ichikawa, 1995: Baroclinic disturbances propagating westward in the Kuroshio Extension region as seen by a satellite altimeter and radiometers. J. Geophys. Res., 100, 839-855.

Deser, C., M. A. Alexander, and M. S. Timlin, 1999: Evidence for a wind-driven intensification of the Kuroshio Current Extension from the 1970s to the 1980s. J. Climate, 12, 1697-1706.

Ducet, N., and P.-Y. Le Traon, 2001: A comparison of surface eddy kinetic energy and Reynolds stresses in the Gulf Stream and the Kuroshio Current system from merged TOPEX/ Poseidon and ERS-1/2 altimetric data. J. Geophys. Res., 106, 16 603-16 662.

- - — and G. Reverdin, 2000: Global high-resolution mapping of ocean circulation from TOPEX/Poseidon and ERS-1 and -2. J. Geophys. Res., 105, 19 477-19 498.

Ebuchi, N., and K. Hanawa, 2001: Trajectory of mesoscale eddies in the Kuroshio recirculation region. J. Oceanogr., 57, 471-480.

Gilson, J., D. Roemmich, B. Cornuelle, and L.-L. Fu, 1998: Relationship of TOPEX/Poseidon altimetric height to steric height and circulation in the North Pacific. J. Geophys. Res., 103, 27 947-27965.

Hurlburt, H. E., A. J. Wallcraft, W. J. Schmitz, P. J. Hogan, and E. J. Metzger, 1996: Dynamics of the Kuroshio/Oyashio current system using eddy-resolving models of the North Pacific Ocean. J. Geophys. Res., 101, 941-976.

Joyce, T. M., 1987: Hydrograhic sections across the Kuroshio extension at $165^{\circ} \mathrm{E}$ and $175^{\circ} \mathrm{E}$. Deep-Sea Res., 34, 1331-1352.

_ I. I. Yasuda, Y. Hiroe, K. Komatsu, K. Kawasaki, and F. Bahr, 2001: Mixing in the meandering Kuroshio Extension and the formation of North Pacific Intermediate Water. J. Geophys. Res., 106, 4397-4404.

Kalnay, E., and Coauthors, 1996: The NCEP/NCAR 40-Year Reanalysis Project. Bull. Amer. Meteor. Soc., 77, 437-471.

Kawabe, M., 1995: Variations of current path, velocity, and volume transport of the Kuroshio in relation with the large meander. J. Phys. Oceanogr., 25, 3103-3117.

Kawamura, H., K. Mizuno, and Y. Toba, 1986: Formation process of a warm-core ring in the Kuroshio-Oyashio frontal zoneDecember 1981-October 1982. Deep-Sea Res., 33, 1617-1640.

Le Traon, P.-Y., and G. Dibarboure, 1999: Mesoscale mapping capabilities of multiple-satellite altimeter missions. J. Atmos. Oceanic Technol., 16, 1208-1223.

Mantua, N. J., S. R. Hare, Y. Zhang, J. M. Wallace, and R. C.
Francis, 1997: A Pacific interdecadal climate oscillation with impacts on salmon production. Bull. Amer. Meteor. Soc., 78, 1069-1079.

Miller, A. J., D. R. Cayan, and W. B. White, 1998: A westwardintensified decadal change in the North Pacific thermocline and gyre-scale circulation. J. Climate, 11, 3112-3127.

Mitchell, J. L., W. J. Teague, G. A. Jacobs, H. E. Hurlburt, and P. J. Hogan, 1996: Kuroshio Extension dynamics from satellite altimetry and a model simulation. J. Geophys. Res., 101, 1045-1058.

Mitsudera, H., T. Waseda, Y. Yoshikawa, and B. Taguchi, 2001: Anticyclonic eddies and Kuroshio meander formation. Geophys. Res. Lett., 28, 2025-2028.

Mizuno, K., and W. B. White, 1983: Annual and interannual variability in the Kuroshio Current system. J. Phys. Oceanogr., 13, 1847-1867.

Niiler, P. P., N. A. Maximenko, G. G. Panteleev, T. Yamagat, and D. B. Olson, 2003: Near-surface dynamical structure of the Kuroshio Extension. J. Geophys. Res., 108, 3193, doi:10.1029/ 2002JC001461.

Nonaka, M., and S.-P. Xie, 2003: Covariations of sea surface temperature and wind over the Kuroshio and its extension: Evidence for ocean-to-atmosphere feedback. J. Climate, 16, 1404-1413.

Pedlosky, J., 1996: Ocean Circulation Theory. Springer, 453 pp.

Qiu, B., 1995: Variability and energetics of the Kuroshio Extension and its recirculation gyre from the first two-year TOPEX data. J. Phys. Oceanogr., 25, 1827-1842.

- 2003: Kuroshio Extension variability and forcing of the Pacific decadal oscillations: Responses and potential feedback. J. Phys. Oceanogr., 33, 2465-2482.

— Kuroshio Extension region. J. Phys. Oceanogr., 23, 2027-2041. , and W. Miao, 2000: Kuroshio path variations south of Japan: Bimodality as a self-sustained internal oscillation. J. Phys. Oceanogr., 30, 2124-2137.

_ S. Chen, and P. Hacker, 2004: Synoptic-scale air-sea flux forcing in the western North Pacific: Observations and its impact on SST and the mixed layer. J. Phys. Oceanogr., 34, 2148-2159.

Schneider, N., A. J. Miller, and D. W. Pierce, 2002: Anatomy of North Pacific decadal variability. J. Climate, 15, 586-605.

Seager, R., Y. Kushnir, N. H. Naik, M. A. Cane, and J. Miller, 2001: Wind-driven shifts in the latitude of the KuroshioOyashio extension and generation of SST anomalies on decadal timescales. J. Climate, 14, 4249-4265.

Smith, W. H. F., and D. T. Sandwell, 1994: Bathymetric prediction from dense altimetry and sparse shipboard bathymetry. $J$. Geophys. Res., 99, 21 803-21 824.

Stammer, D., 1997: Steric and wind-induced changes in TOPEX/ POSEIDON large-scale sea surface topography observations. J. Geophys. Res., 102, 20 987-21 009.

Taguchi, B., S.-P. Xie, H. Mitsudera, and A. Kubokawa, 2005: Response of the Kuroshio Extension to Rossby waves associated with the 1970s climate regime shift in a high-resolution ocean model. J. Climate, 18, 2979-2995.

Tai, C.-T., and W. B. White, 1990: Eddy variability in the Kuroshio Extension as revealed by Geosat altimetry: Energy propagation away from the jet, Reynolds stress, and seasonal cycle. J. Phys. Oceanogr., 20, 1761-1777.

Talley, L., 1997: North Pacific Intermediate Water transports in the mixed water region. J. Phys. Oceanogr., 27, 1795-1803.

Teague, W. J., M. J. Carron, and P. J. Hogan, 1990: A comparison 
between the Generalized Digital Environmental Model and Levitus climatologies. J. Geophys. Res., 95, 7167-7183.

Toba, Y., and H. Murakami, 1998: Unusual behavior of the Kuroshio current system from winter 1996 to summer 1997 revealed by ADEOS-OCTS and other data-Suggestion of topographically forced alternating-jet instability. J. Oceanogr., 54, 465-478.

Vivier, F., K. A. Kelly, and L. Thompson, 2002: Heat budget in the Kuroshio Extension region: 1993-99. J. Phys. Oceanogr., 32, 3436-3454.

Wang, L., C. J. Koblinsky, and S. Howden, 1998: Annual and intra-annual sea level variability in the region of the Kuroshio
Extension from TOPEX/Poseidon and Geosat altimetry. $J$. Phys. Oceanogr., 28, 692-711.

Wijffels, S. E., M. M. Hall, T. M. Joyce, D. J. Torres, P. Hacker, and E. Firing, 1998: Multiple deep gyres of the western North Pacific: A WOCE section along $149^{\circ}$ E. J. Geophys. Res., 103, 12 985-13 009.

Yasuda, I., K. Okuda, and M. Hirai, 1992: Evolution of a Kuroshio warm-core ring-Variability of the hydrographic structure. Deep-Sea Res., 39, 131-161.

- - - and Y. Shimizu, 1996: Distribution and modification of North Pacific Intermediate Water in the Kuroshio-Oyashio interfrontal zone. J. Phys. Oceanogr., 26, 448-465. 